married twice, the second time late in life. He has had many threatenings of a break-down, and once had anginoid symptoms. Professor Gairdner informs me he is still living, and continues his practice. He took mach digitalis, and lost his murmur ; two months ago he reported himself comfortable and well. I am indebted to the kindness of Dr. G. W. Balfour, of Edinburgh, for the history of a case in which there was one attack only of rheumatic fever, at the age of eleven or twelve years. The patient is a policeman, married, over 40 years of age, living at the top of a high house in Edinburgh. Many years ago, Dr. Littlejohn accidentally discovered an aortic murmur in this case. This man has now a heart, as Dr. Balfour describes it, like an ox, with loud double aortic murmurs, and he is now failing, having only had cardiac symptoms for a few weeks, following a bad attaok of bronchitis. This case has been absolutely symptomless for nearly thirty years. I think it is hardly to be doubted that the records of mest life-insurance offices would add testimony to the fact that cases of rheumatic valvulitis live on for long periods without the occurrence of serious symptoms. Our proposed inquiry will be largely aided, if medical officers of assurance societies will procure the testimony needed.

Respecting mitral reflux, Sir Andrew Clark reports a case of a gentleman who was condemned to die in less than six months, and who, forty years afterwards, was enjoying good health; and also one where the patient was living, in fair health, forty-two years subsequently, at the age of 85 , (Proceedings of Med. Soc. of Lond., p. 49, 1877-79). Dr. Semple (Diseases of the Heart, p. 114. tondon, 1875) has recorded a case of mitral and aortic valvulitis, after five attacks of rheumatic fever, in a lady, in whom the disease has existed for thirty years. She is now in New Zealand, and is, Dr. Semple informs me, still in good health. In the museum at St. Bartholomew's Hospital, are several specimens, taken from patients who appear to have been long free from symptoms of heart-disease. In one there is sclerosis of the mitral valve, with vegetations on it, and on the left auricular wall; a pendulous vegetation is also attached to an aortic cusp. This came from a woman, aged 27 , who had attacks of rhoumatic fever at the ages of 16 and 23. She had a loud murmur at the apex, audible behind. She had no inconvenience from her heart, and died of acute nephritis with anæmia.

In another specimen there are but two aortic and two pulmonary valves. These and the tricuspid and mitral valves are all thickened. The aortic valves are quite rigid and stonosed. The whole heart is enlarged proportionally in its several parts. This came from a man, aged 30, who had rheumatic fever fifteen years before death. There were no symptoms till a year before his death, when he had dyspnce on exertion, much increased in the last week of life. Anasarca only existed for three days at the last. Murchison (Path. Suc. Trans., vol. xix, p. 100,1865 ) recorded a case of mitral and aortic disease in a man, aged 45, who had rheumatism eight years previously, had drank freely of beer, and went on without any symptoms till within six months of his death, from cardiac failure, rupture of the right ventricle (which was fatty), and rupture of an aortic valve. I have under my care a lady, who has had mitral reflux without any serious symptoms for nearly ten years. The lesion began insidiously. There was gouty history in the family.

Dr. Walshe has met with two or three cases with imperfect second sound at the aortic base, which have suggested imperfect closure of the valves, and which have passed on to perfect reflux. These cases were void of all symptoms. I have seen several of such cases, and have now two of rheumatic origin under my care at this time. This would indicate that incipient aortic regurgitation may be a symptomless lesion, and as much might, perhaps, have been predicated.

Dr. Fothergill (The Diseases of the Heart, p. 500, 2nd edit., 1875) records two noteworthy cases of aortic disease. In one, a medica man, had thus suffered often for twenty years. $\mathrm{He}$ had had serious attacks occasionally, but had recovered from them. He had led a very active life, and the disease made no progress. In the other, a woman over forty years of age, there had been signs of aortic reflux for more than twenty years. She had an enormous left ventricle. It is not, however, stated if these were cases of rheumatic disease. Dr. King Chambers (Lectures chiefly Clinical, etc., p. 307, 4th edit., 1865) has recorded cases of valvular cardiac diseases, of long standing, many of thom of rheumatic origin. He seldom refers to the special valves affected, and only mentions that murmurs were present. The histories were taken from-private practice, and from insurance examinations. There was evidence, in these cases, of great prolongation of life from the time of the original rheumatic attack, and the periods varied from one to fifty-seven years. In most of these cases, eighteen in number, there wer no symptoms, and lew that could be called serious, save some anginal attacks in a case of aortic disease, in a lady, which had lasted seven years. Dr. Chambers remarks, upon this series of cases, that " you know very well that cases like these are not to be met with in hospital practice, or among the paupers in a workhouse." They are, indeed, only found amongst patients of the well-to-do class, who are able to live carefully, without exposure to poverty and hard labour. Dr. Walshe gives me his experience, to the effect that it was very common to meet with examples of mitral reflux, aortic stenosis and reflux, running on for years, without symptoms fairly traceable to valvular defect. He has known cases, observed by himself from the first, of mitral reflux remain functionally innocuous for upwards of twenty years. Cases of aortic regurgitation, which are symptomless, he has not found to be commonly of rheumatic origin.

[To be continued.]

\section{CONGENITAL CLUB-FOOT.}

THE PART PLAYED BY THE TARSAL LIGAMENTS IN MAINTAINING THE DEFORMITY ; AND THE VALUE OF THEIR SUBCUTANEOUS SECTION IN ITS CURE.

By ROBERT WILLIAM PARKER, M.R.C.S.Eng.,

Surgeon to the East London Hospital for Children, and to the Grosvenor Hospital for Women and Children.

For some years past, I have been much occupied in the study of the anatomical conditions existing in congenital club-foot, and, in con junction with my friend Mr. Shattock, I contributed to the Pathological Society a paper on the subject, which appeared in the Transac. tions of that Society for the year 1884. I may very briefly say of that paper, that it was commenced without reference to the conclusions at which Mr. Shattock and I both arrived, long before we had finished it: When we commenced the study of club-foot, we were both dominated by what, I believe, is the most widely accepted doc. trine as to its mode of causation; namely, that it is either a paralysis or a spasmodic contraction of certain muscles of the leg acting upon the foot. Neither of us was prepared to find the nerve-centres, the nerve-trunks, and the muscles of the afflicted limb in a state of absolute histological integrity; neither of us was prepared to find that, after all the soft parts had been entirely removed from the limb, the deformity would persist in just as marked a degree, and in just as intractable a form, as previously to the dissection. Yet such was the case. My object in this paper is not to merely repeat the substance of what I said at the Pathological Society, but rather to advocate the practical lessons which, I venture to think, this anatomical condition imposes on all who are concerned with the treatment of club-foot.

Brief Abstract of the Anatomy of Congenital Club-Foot.-In a not inconsiderable number of cases of club-foot, which I have had the opportunity of dissecting during the past four or five years, mostly still-born children at term, but including also three cases in children ranging from 6 to 18 months of age, the only constant condition, which I have found, has been inability to overcome the deformity (even after removal of all the muscles), until some of the ankle and tarsal ligaments have been divided. This condition of ligaments can hardly be described as a shortened condition, because such a term would imply that, once long enough, they have in some way or other become shortened; and this is not in accordance with the actual facts. These ligaments are short, but they are not shortened; they are as they have been dereloped; they are in the same condition as certain of the muscles, that is to say, shorter than normal, owing to the fact that the points of attachment have been unduly approximated during development and growth. Microscopic examination of the muscles shows them to be histologically normal in all respects in early infancy; the nerve-trunks also, and the spinal cord, show a healthy structure; the full supply of normal ganglionic cells was particularly striking in the lumbar enlargement of the spinal cord in the cases examined, and shown at the Pathological Society.

As regards the bones of the tarsus, I may say that, although an exaggerated inclination inwards and forwards of the neck of the astragalus was found in the great majority of cases, yet this condition was not marked case the inclination in wards was much below the average amount found in the infantile normal astragalus, a fact which demonstrates that this conformation of the astragalus is not only not the :essential element of the, deformity, but also that it is not even a necessary part of it The average amount of this obliquity in club-foot is $49^{\circ}$, while, the maximum has reached as high as $64^{\circ}$ in my own cases. Some authors 
have even described the neck of the astragalus as pointing directly inwards. The average normal obliquity amounts to $38^{\circ}$. In one case of talipes; it amounted to only $31^{\circ}$. A comparison between the human talipedic astragalus, and that of the ourang-outang, shows how nearly the former approximates the latter.
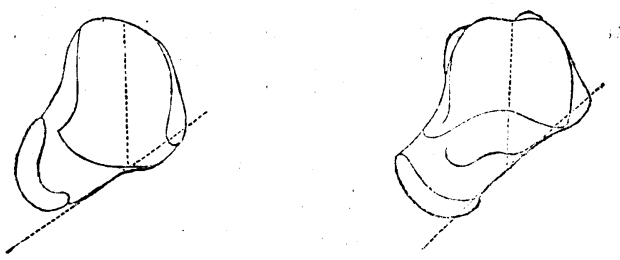

Fig. 1.-Talipedic astragalus from chili, aged 18 months. Natural size. Obliquity of neck, $=53^{\circ}$.

Fig. 2.-Astragalus from ourang-outang. Reduced one-third. Obliquity of neck,

This peculiar conformation of the astragalus appears to be associated with the great power of inversion which the fœtal and infantile foot enjoys, a movement which, in the anthropoid apes, is one of the characteristics of the pes throughout life; it is as little pathognomonic of the condition of talipes in the one as in the other. The calcaneam likewise presents a slight incurvation; that is to say, the outer margin of the bone is more convex than normal, and the cuboid surface, instead of looking forwards, looks forwards and inwards. This incurvation is probably produced by the traction made on the bone through the external calcaneo-cuboid ligament. In congenital clubfoot, all the constituent bones are slightly altered in shape; they present, when seen in horizontal section, as in Fig. 3, a slight incurvation; in severe cases, this may be very accentuated. The importance of taking cases of congenital club-foot in hand very early, before ossification of the bones has occurred or had time to complete itself, becomes abundantly manifest ; for the bones, once fairly ossified in this incurved condition, will oppose themselves, with all the strength of an arch, to rectification, which will then become exceedingly difficult, not to say impossible.

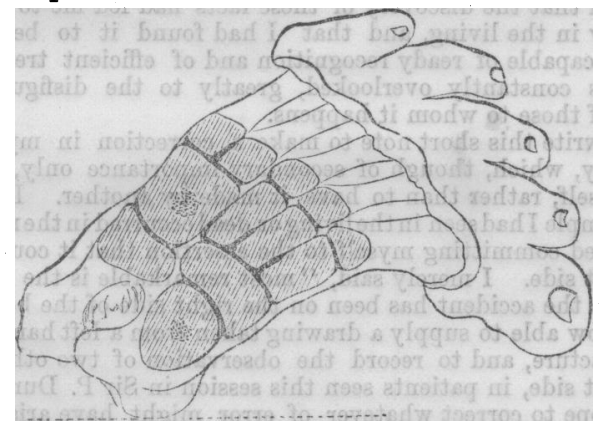

Fig. 3.-Horizontal section through talípedic foot. Reduced one-third.

As regards the ligaments, structurally I have not found any changes at all. The condition, which is abnormal in them, is again purely anatomical and consists in an altered and abnormal mode of attachment. Talipes, in the great majority of cases, is a deformity only because it is a fixed position; it is a physiological position at one or other period of foetal life; it has become pathological, owing to the fact that the assumption by the foot of the other (physiological) positions, which are necessary for the due development of all the parts concerned in the production of these movements, has been interfered with.

These anatomical details will strike other surgeons than myself, and their bearing on treatment will hardly need emphasising at my hands.

Subcutaneous Division of Ligaments as a means of Treatment.-I am not going to enter into the details of the treatment usually applied to talipes; as is well known, this treatment is partly operative and partly mechanical, the latter monopolising the greater share. I wish rather to advert to what I consider the insufficiency of this treatment, and to propose the adoption of such further measures as the knowledge of the foregoing anatomical considerations naturally suggests. The ligaments chiefly at fault are those placed on the inner botder of the deformed foot namely, the anterior portion of thi internal lateral ligament of the ankle, the astragalo-scaphoid, and the calcaneosoaphoid ligaments, all three being blended into one indistinguishable capsule of great strength (spoken of in this paper as the " astragaloscaphoid capsule"); in a less degree, the capsular ligaments betwreon the scaphoid and the internal cuneiform bone, and between the latter and the first metatarsal bone, are at fault. In the severest casesthose which have relapsed, and have been walked upon-in which the patient walks upon the dorsum pedis, and in whom the outer edge of the foot is greatly inverted, the long and short (calcaneo-cuboid) plantar ligaments will be found short. Hencé it follows that tonotomy leaves the major part of the anatomical conditions unaltered. With the exception of the calf-muscles, represented by the tendo Adoillis, I believe, in the majority of cases, that the muscles of the leg may be left out of consideration; that is to say, I believe they may be elongated to the required extent by systematic manipulation. If the ligaments and the muscles were equally extensile (which they are not), it is evident that more gain would be expected from the muscles than from the ligaments, on account of the difference in length; in the former, there is more material, to gain upon; the latter are so extremely short, that we cannot expect much gain from stretching them; moreover, an unyielding nature is one of the characteristics of ligamentous structures. For these reasons, therefore, I would urge subcutaneous division of the tarsal ligaments, whenever the short condition of these structures prevents the unfolding and rectification of club-foot. I have practised the method a good many times during the past three or four years, and with uniformly satisfactory results. The time necessary to the rectification of a severe case of talipes is materially shortened, the chances of relapse are lessened, and the treatment of this congenital deformity is placed on a sound anatomical basis.

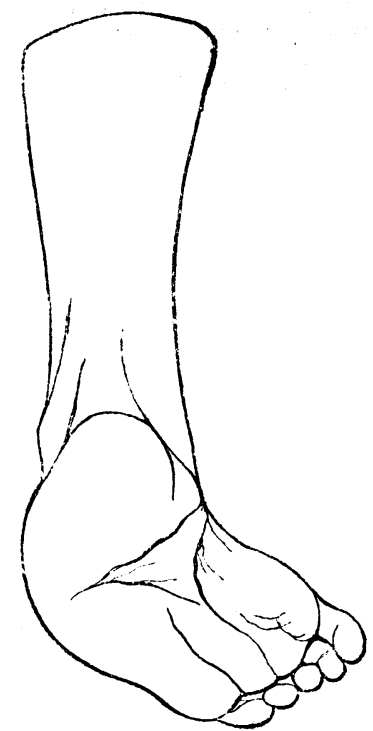

Fig. 4. - The sole of a talipedic foot. The transverse line in front of the heel corresponds to the chief ligamentous attachments.

The adjoining woodcut is taken from a plaster cast of a foot, on which I operated as just described, about twelve months ago. The transverse line in front of the heel indicates very well the position occupied by the ligaments above alluded to, or rather the points at which they exercise their power of resistance. The inner extremity of the transverse line corresponds to the astragalo-scaphoid capsule, the outer extremity to the calcaneo-cuboid capsule; and it is in this line that section of the ligaments may most advantageously be made. The posterior ligament of the ankle may occasionally require dividing in cases where the equinus rortion of the deformity is much marked This is best accomplished by means of a small spear-headed knife, which should be passed through the tendo Achillis in the direction of its fibres, and then turned flatways, and passed through the posterior ligament about its middle, cutting first on one side and then on the other. Most authors refer to the difficulty of flexing the ankte after division of the tendo Achillis in certain cases, and attribute this to adhesions in the sheath of the tendon, rather than to its true cause, the short condition of the posterior ligament of the ankle.

Rules for the Division of Ligaments. - The ligament which will most frequently need division is, fortunately, quite sabcutarieous, can be easily reached, and divided without any risk to other structures. 
The "astragalo-scaphoid capsnle" extends from the tip and sides of the internal malleolus across the astragalo-seaphoid articulation, on to the internal cuneiform bone, and loses itself in a fibrous expansion, blending with ather ligaments on the fore part of the inmer border of the foot. The extent and dinection of the fibres which chiefly oppose rectification of the foot can be felt with the finger-tip, when traction is made on the inverted foot.: A curved tenotome shauld be entered immediately in front of the anterior border of the internal malleolus, the ibiude as far as possible being kept between' the ligamenta to be divided and the superjacent skin. In the next stage of the ipenation, the blade is to be turned against the surface of the ligamerit, and, by meang of a gentlo sawing motion, is made to divide it. : As the superficial fibres are divided, deeper anes come into play, and must in their turn be divided antil bone is : behedi. By keeping the knife close to the bones, and directing its point towards the plantar aspect, the calcando-scaphoid Higament; which forms an important part of the capsule in these cases, can be easily divided. In this operation, the tendon of the pontenior tibial muscle will almost certainly be divided, and not im probably that also of the anterior tibial muscle. The long and short plantar (calcaneo-cuboid) ligaments can most effectually. be reached just where' they pass between the two bones. A straight tenotome must be entered as nearly as possible over the calcaneo-caboid articalation on the outer edge of the foot. If there be much inversion this point will appear to be on the sole of the foot. The blade must be kppt close to the bone, and be made to follow the direction which - His articulation takes. In this manner, the two ligaments, mostly blonded together at this point, will be divided simultaneously.

I append the forms of tenotome which I have found most useful in children. They differ from those in ordinary use, chiefly in the fact that the stem is longer and the cutting blade shorter. They were made for me by Mayer and Meltzer; the drawings have accidentally been made quite one-third larger than the knives themselves.

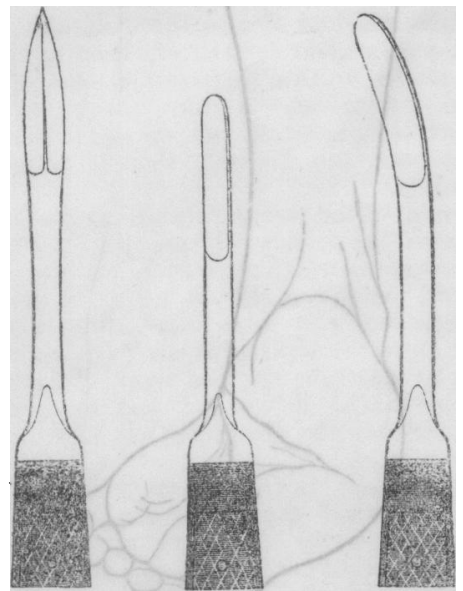

Figs. 5, 6, and 7.-Tenotomes; these sizes must be considerably reduced for infants.

The success of all such operations depends on the smallness of the external incision; that is, on their being subcutaneous. I therefore prefer a short cutting blade, as I think the danger of enlarging the external wound is lessened thereby. If it be intended to divide several structures at the same sitting, I should recommend an ancesthetic to be given, and that an Esmarch's bandage be applied. In this manner, all undue hæmorrhage is prevented. I would just add that general rigidity of the foot is a means of gauging the extent to which the ligaments, being affected, need division. This rigidity depends partly on their unyielding nature, and partly on their shortness. Even in contracted muscles, there is always more or less elastieity, dependent, among other things, on their length. The subisequent treatment of these cases is simple enough. My practice is to rectify the foot as much as possible; and to-apply a plaster-of-Paris bandage. I leave this first dressing undisturbed for a week or a fortnight, in order that healing of the cutsneous wound may complete itealf. After this period, manipulations, etc., may be commenced. I shall not enter into these well known details ; each case must, of course, be treated in relation to its special requirements.

It must not be supposed that syndesmotomy (section of the liga ments) is necessary in all cases; or that this operation alone will cure club-foot, any more than tenotomy cures it. More- orer, there will always be a residuum of cases for which neither the one nor the other operation will suffice, and in which tarsectomy, in some form, will have to be entertained. But the subcutaneous, or oven the open, division (for the skin itself is often no mean factor in resisting rectification of the foot), in suitable cases, of the strong unyielding ligamentous structures which I have shown by dissection to be constantly implicated in this deformity, will, I venture to think, not only secure a better result, but lessen the tendency to relapse, and reduce the length of time necessary to effect a cure.

\section{ON FRACTURE OF THE METACARPAL BONE OF THE THUMB.}

By EDWARD H. BENNETT, M.D. Professor of Surgery in the University of Dublin; Ex-President of the Royal

A the meeting of the British Medical Association, held atCardifflast summer, I referred in the remarks I made in opening the session of the Surgical Section, amongst other matters, to the subject of fracture of the metacarpal bone of the thumb. (BRrrish MEDICAL Journal, August 1st, 1885.) I directed attention to the fact that the most common simple fracture of this bone, and of the entire metacarpus, had been overlooked until the publication by myself of a note of the injury in 1881. (Proceedings of Dublin Pathological Society, Dublin Journàl of Medical Science, vol. Ixxiil, p. 72.) In support of my statement, I exhibited in the Pathological Museum of the Association, then open, a collection of these fractures, united, six in number, all bones from the right hand. Beside them, I placed the entire collection of similar fractures of the remaining bonres of the metacarpis in our collection, which had been obtained without any attempt at selection of individual bones, or any knowledge of the relative frequepcy of fracture in them. These are, in all, nine, two from one hand and seven from separate individuals.

I stated that the discovery of these facts had led me to look out for the injury in the living, and that I had found it to be sufficiently common, capable of ready recognition and of efficient treatment; but that it is constantly overlooked, greatly to the disfigurement and damage of those to whom it happens.

I now write this short note to make a correction in my account of the injury, which, though of secondary importance only, I prefer to make myself, rather than to have it made by another. I stated that every example I had seen in theliving or dead occurred in the right thumb.

I avoided committing myself to the assertion that it could not occur on the left side. I merely said, "most remarkable is the fact that in every case the accident has been on the right side of the body."

I am now able to supply a drawing taken from a left hand, deformed by the fracture, and to record the observation of two other examples on the left side, in patients seen this session in Sir P. Dun's Hospital. Thus I hope to correct whatever of error might have arisen from my record of my experience in August last. This correction appears called for by the observations contained in the review of my address, published in this JOURNAL, from which I quote the following: "It will, no doubt, soon appear whether our author is correct in affirming the frequency of this injury, and its constant limitation to the right hand; for the matter is one of too much daily interest, both to surgeon and patient, to be overlooked."

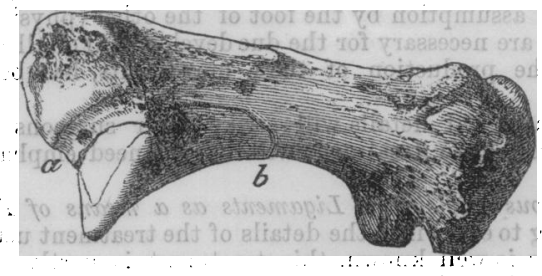

Fig. 1.

To rander this note intelligible to those who may read it without requiring them to refer to my previous' statements, I republish the original sketch of the fracture (Fig. 1), and also woodcuts taken from the left and riglut hands deformed by the injury, abandoned to the natural means of recovery only.

For compariopn with these illustrations, I have copied Hamilton's 